$17^{\text {th }}$ International Congress of Metrology, 08001 (2015)

DOI: $10.1051 /$ metrology $/ 201508001$

(C) Owned by the authors, published by EDP Sciences, 2015

\title{
A European project to enhance process efficiency through improved temperature measurement: EMPRESS
}

\author{
J.V. Pearce ${ }^{1}$, F. Edler ${ }^{2}$, C.J. Elliott ${ }^{1}$, L. Rosso ${ }^{3}$, G. Sutton ${ }^{1}$, R. Zante ${ }^{4}$, G. Machin ${ }^{1}{ }_{1}$
}

\author{
National Physical Laboratory (NPL), Teddington, United Kingdom \\ 2 Physikalisch-Technischen Bundesanstalt (PTB), Berlin, Germany \\ 3 Istituto Nazionale di Ricerca Metrologica (INRiM), Turin, Italy \\ ${ }_{4}$ Advanced Forming Research Centre (AFRC), Glasgow, United \\ Kingdom
}

\begin{abstract}
Résumé. Nous décrivons un nouveau projet européen appelé impératrice, financé par le Programme européen d'innovation et de recherché en métrologie (EMPIR). Ce projet commencera pendent l'été 2015, et durera triois années. Il permettra d'améliorer de manière significative l'efficacité des processus de fabrication de haute valeur en améliorant la capacité de mesure de température. Le consortium du projet compte 18 partenaires, de la communauté de la métrologie (NMI et DI), l'industrie manufacturière de haute valeur, fabricants de capteurs de température, et le milieu universitaire. Le contrôle précis de la température garantit l'efficacité des processus et la qualité du produit. L'amélioration de l'efficacité des processus peut prendre plusieurs formes, notamment: la réduction du rejet de produits / déchets; une meilleure efficacité énergétique; l'augmentation des intervalles entre les vérifications de capteur / entretien; et la fiabilité accrue du capteur, ce qui minimise la fréquence d'intervention de l'opérateur. La traçabilité des mesures de température à l'échelle internationale de température de 1990 (ITS-90) est un facteur critique pour l'incertitude de mesure et la reproductibilité ainsi que pour la qualité et l'efficacité du contrôle de processus permettre cette traçabilité in situ (c'est-à-dire dans le processus industriel) est un thème récurrent dans ce
\end{abstract} projet.

\section{Introduction}

High value manufacturing depends on reliable temperature control, for example in the aerospace sector accurate, traceable temperature measurement is essential for applications up to and above $1300{ }^{\circ} \mathrm{C}$ such as casting, forging and sintering. In general there is a requirement for more stable sensors and standardisation of at least one new thermocouple type to fill the gap between $1500{ }^{\circ} \mathrm{C}$ and $1800{ }^{\circ} \mathrm{C}$. Above $1800{ }^{\circ} \mathrm{C}$ only W-Re thermocouples are widely available but their erratic performance renders them very unsatisfactory for long-term measurement. At lower temperatures below $500{ }^{\circ} \mathrm{C}$, forming of metal and composites requires tight temperature control which is challenging, and current measurement methods are limiting the uptake of new, more efficient furnace technology. Measurement of combustion temperature is extremely difficult and prone to large errors; for example, thermocouple measurements of flame temperatures can be in error by hundreds of degrees. In the latter case what is required is a portable 'standard flame' whose temperature is traceably calibrated, which may be used to calibrate other combustion sensors or measurement methods.

This article describes a project funded by the 2014 Industrial call of EURAMET's European Metrology
Programme for Innovation and Research (EMPIR) entitled 14IND04 EMPRESS (enhanced process control through improved temperature measurement). This project both builds on the European Metrology Research Programme (EMRP) project HiTeMS [1] and introduces a number of completely new research approaches. The consortium

comprises 18 partners from the metrology community (National Metrology Institutes (NMIs) and Designated Institutes (DIs)), high value manufacturing industry, and academia; details are given in Section 3 below. Through this project the uncertainty of temperature measurement in high value manufacturing processes will be significantly reduced by developing new sensors which are less susceptible to calibration drift in-process; introducing traceability to the International Temperature Scale of 1990 (ITS-90) [2] directly into the process; and through developing novel calibration techniques. The potential range of applications is very large but this project focuses on in-process measurements where the need for improvement is greatest: those using thermocouples, surface contact probes, and combustion thermometry. 
The project has four scientific and technical objectives, one per workpackage (WP). Each WP targets a specific problem concerning process temperature measurement. Through fulfilling all four objectives, process efficiency will experience a step change improvement. The realisation of these improvements in industry will be facilitated by the fifth WP concerning impact and knowledge transfer. The WPs are as follows:

- WP1: To develop novel low drift temperature sensors for enhanced production and temperature control. The objective is to develop new sensors, suitable for high data capture rate, in the same format as current sensors. The target is to have in-process traceable uncertainty of better than 3 ${ }^{\circ} \mathrm{C}$ at temperatures around $1450{ }^{\circ} \mathrm{C}$, and better than $5{ }^{\circ} \mathrm{C}$ at temperatures $>2000{ }^{\circ} \mathrm{C}$ over about 3 months continuous use.

- WP2: To develop non-drift contact sensors optimised for heat treatment applications to temperatures around $1350{ }^{\circ} \mathrm{C}$. The sensors should be able to remain in service with a stability of better than $1{ }^{\circ} \mathrm{C}$ for at least 6 months. The sensors will be trialled in-process in at least one industrial setting, e.g. heat treatment of gas turbine components.

- WP3: To develop traceable surface temperature measurement methods to enhance materials/chemical processing to around $500{ }^{\circ} \mathrm{C}$. The methods should allow the calibration of surface temperature sensors, using at least one novel surface temperature approach and be used to demonstrate improved temperature measurement in at least two industrial settings, e.g. forming and forging.

- WP4: To develop an in-situ combustion standard of known temperature for the validation of flame temperatures. The combustion standard should have an uncertainty a factor of 10 lower than current methods and be tested in at least two industrial settings.

- WP5: To ensure that the outputs from the project are effectively disseminated to and exploited by the high value manufacturing sector (e.g. automotive, aerospace, casting, heat treatment, sensor manufacturers). To support the development of new, innovative products and services enhancing the competitiveness of EU industry.

\section{The project}

The European aerospace industry employs over 500,000 people [3] distributed throughout the EU (2008 figures, encompassing the entire supply chain). Turnover of aeronautics and space activities in Europe in 2008 was $€ 105$ billion [3]. Key areas of research and development are: improving engine efficiency [4] by maximising the temperature rise through the combustor [5]; reducing airframe weight by using new materials; and implementing more efficient production processes [5]. All of these require improved temperature measurement capabilities. Facilitating links between the EU Member States and their collaboration on matters of aviation research has been identified as a priority by the Advisory Council for Aeronautics Research in Europe (ACARE). In particular, ACARE recommended a $50 \%$ reduction of greenhouse gas emissions per passenger kilometre by concentrating on reducing airframe weight and increasing engine fuel efficiency in equal measure [6].

There are important gaps in temperature measurement capability in the aerospace sector, with heat treatment and forging of components, casting of exotic single-crystal alloys, and combustion temperature measurement suffering from large uncertainties. Challenges remain for gas turbine manufacturers and heat treatment providers in mitigating drift of noble metal thermocouples which are used almost exclusively for process control in these applications. Improved thermocouples, optical sensing techniques, and in-situ self-validation techniques in WP1 and WP2 will improve the situation.

The reduction of weight of aircraft components is being addressed by developing new composite materials and lighter aluminium alloys (the new Airbus A350 XWB airframe is $53 \%$ composite, and $33 \% \mathrm{Al}$ and $\mathrm{Ti}$ alloys; the wings are nearly $100 \%$ composite). However, this introduces new challenges associated with welding, forging, and forming, which in turn places new demands on surface temperature measurement to ensure adequate pre- and post-welding/forming heat treatment. Improved forming techniques are identified as a priority in the EU publication 'factories of the future' [7]. WP3 on improved (and traceable) surface temperature measurement and novel probe calibration techniques will solve many of the problems currently experienced by manufacturers relying on conventional contact surface probes.

Another challenge is accurate temperature measurement in combustion and flame processes, which is important for materials manufacturing, fire testing, and gas turbine engine development. Traceably calibrated standard flames in WP4 will substantially improve current combustion temperature measurement techniques, as will in-situ flame temperature measurement techniques. Currently, traceability of combustion thermometry to national standards does not exist.

The range of proposed temperature measurement improvements in this project have the potential to reduce energy consumption, improve yield, improve consistency and reliability, reduce emissions, and enhance overall process efficiency. Many modern industries have a global presence: parts are manufactured and brought together from diverse locations for assembly; assured in-process traceability of measurements to the ITS-90 is essential for product consistency and reproducible processes: this is built-in to all the solutions proposed in this project.

2.1 WP1: Low-drift contact temperature sensors The current state of the art for contact thermometry measurements between $1300{ }^{\circ} \mathrm{C}$ and $1600{ }^{\circ} \mathrm{C}$ comprises 
noble metal thermocouples, Type R (Pt-13\%Rh vs. Pt), Type S (Pt-10\%Rh vs. Pt), and Type B (Pt-30\%Rh vs. $\mathrm{Pt} 6 \% \mathrm{Rh})$. These are known to drift, often by several degrees, and in an unpredictable manner, so their performance potentially limits the efficiency of a number of advanced manufacturing processes such as specialist casting and heat treatment of critical aerospace components. Above about $1700{ }^{\circ} \mathrm{C}$ only the W-Re thermocouple contact sensor is routinely available; this can be subject to drift of $>10{ }^{\circ} \mathrm{C}$ over a short timescale (see Figure 1) and has an uncertainty when new of $1 \%$ of temperature $\left(20^{\circ} \mathrm{C}\right.$ at $\left.2000{ }^{\circ} \mathrm{C}\right)$.

A key standard for the aerospace manufacturing supply chain is AMS 2750E [8] which specifies the temperature measurement and control requirements for a number of aspects of manufacturing. Importantly, although the standard specifies calibration intervals for particular thermocouple types, it also states that the user is responsible for ensuring that excessive drift has not occurred during the process.

The aim of this WP is to identify new thermocouples based on Pt-Rh alloys with superior thermoelectric stability (to $1800{ }^{\circ} \mathrm{C}$ ) to the standard Type R, S, and B, which, although in widespread use, for historical reasons are not necessarily optimal in performance [9], and develop a reference function (standard thermovoltagetemperature relationship) of the new optimal type to supplement the current provisions of the ASTM E1751 standard [10]. The stability and reference function will be established using high temperature fixed points (HTFPs) based on metal-carbon eutectic alloys [11]. The state of the art at temperatures above $1800{ }^{\circ} \mathrm{C}$ will be progressed by developing carbon thermocouples with a stability of better than $5{ }^{\circ} \mathrm{C}$ above $2000{ }^{\circ} \mathrm{C}$, as demonstrated by trials in an industrial process. For processing environments where thermocouples are not suitable in the temperature range from $1100{ }^{\circ} \mathrm{C}$ to 1900 ${ }^{\circ} \mathrm{C}$, this project will advance the state of the art by developing optical-based sensors using single-crystal sapphire light guides attached to a miniature blackbody, with a target uncertainty of less than $1{ }^{\circ} \mathrm{C}$.

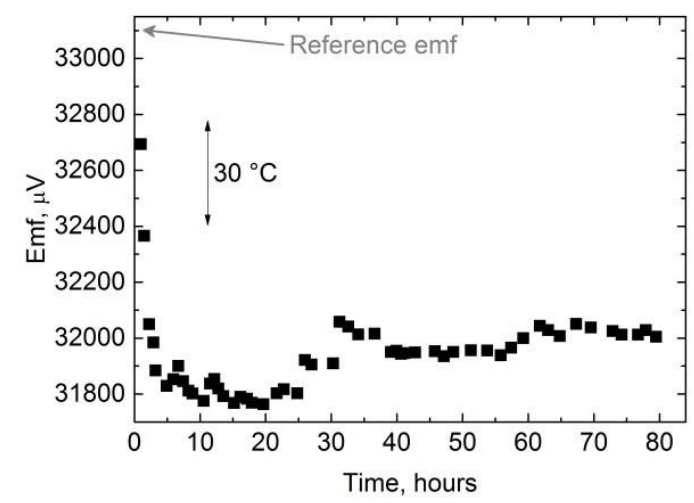

Figure 1. Stability of a refractory Type C (W-Re) thermocouple [12] at about $1954^{\circ} \mathrm{C}$, as measured by repeated melting of a RuC HTFP. The instability and rapid drift of the emf are evident.

\subsection{WP2: Zero-drift contact temperature sensors} For long-term measurements, e.g. heat treatment and creep testing, the unknown drift of the control or monitoring thermocouples can cause serious errors in the reading, leading to loss of production/information. The principal mitigation method is to replace the sensors at frequent intervals, which is costly and potentially disruptive to the process. The state of the art will be advanced in this project by a) developing and trialling inprocess self-validating thermocouples, eliminating the cost and time penalties incurred by continual process interruption; and b) trialling, in-process, new mineralinsulated metal-sheathed (MI) cable as a more stable substitute for the commonly used base metal Type $\mathrm{N}$ thermocouples. Self-validating thermocouple prototypes, which make use of a HTFP reference with invariant melting temperature mounted on the tip of a thermocouple to provide traceable in-situ calibration (Figure 2), have been successfully used with refractory thermocouples in a space application $[13,14]$. This project will reduce the dimensions of the fixed-point artefacts to a size commensurate with use in industrial environments i.e. without requiring new sensor placements. The aim will be to obtain temperature measurement uncertainty, in-process, for Pt-Rh thermocouples of less than $1{ }^{\circ} \mathrm{C}$ up to $1500{ }^{\circ} \mathrm{C}$ for at least 6 months' use.

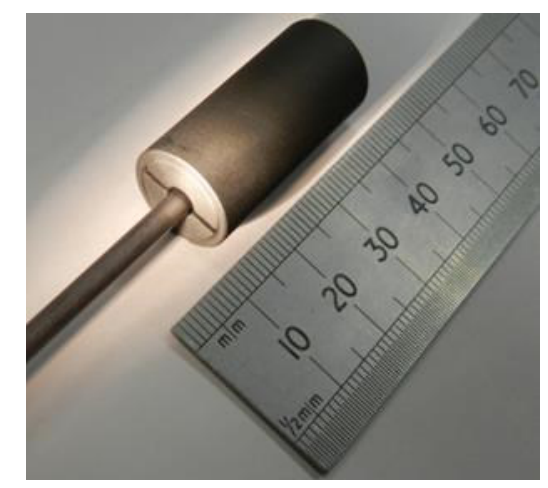

Figure 2. Concept of the self-validating thermocouple, showing a HTFP cell surrounding the thermocouple tip.

\subsection{WP3: Traceable surface temperature measurement with contact sensors}

For temperatures up to about $500{ }^{\circ} \mathrm{C}$, surface temperature measurement by contact thermometry is very problematic, and yet critical for a wide range of industrial processes. For example, in welding applications the use of temperature sensitive crayons to determine pre- and postweld temperature is widespread, but the results are very subjective and non-traceable. Furthermore, in the production of advanced aluminium alloys, the control of the pre-heating temperature of the billets for the hot forming process inside new generation rapid infra-red furnaces is critical.

Surface contact sensors are used but poorly characterised and also prone to subjectivity. Infra-red thermometry is beset with emissivity and reflected thermal radiation problems which often give rise to readings in error by tens or even hundreds of degrees, and is not robust enough for routine use, for example in the marine manufacturing sector. More advanced techniques such as phosphor thermometry and dynamically 
compensating sensors (which compensate errors due to stray heat flows) are difficult to obtain commercially and are often not suitable for use by process engineers. These new techniques need to be adapted for use in high value manufacturing processes. Post-weld heat treatment temperature is an essential variable in all of the key welding procedure specifications, which often require tight tolerances on temperature measurements of the order of $\pm 10^{\circ} \mathrm{C}$. This is currently unrealistic given the many sources of uncertainty in the measurement: despite sensors having manufacturer stated accuracy of the order of $0.3{ }^{\circ} \mathrm{C}[15]$, in reality errors of tens of degrees may arise, varying widely with the surface type [16]. Standards governing coating of metals require surface thermometers accurate to $\pm 0.5{ }^{\circ} \mathrm{C}$ [17]. This accuracy, for this type of thermometer, is currently unachievable. An alternative to conventional approaches for measuring surface temperature is fluorescence thermometry, which involves irradiating a phosphor applied to the surface with light and observing the decay in the radiant intensity, which is a characteristic function of temperature. By painting a phosphor onto a surface, the surface temperature may be obtained without the heat flow problems associated with contact thermometers, and without the problem of unknown emissivity that besets non-contact thermometry. The goal of this WP is to develop two new techniques for traceably calibrating contact temperature probes based on fluorescence thermometry [18] (Figure 3) which is free from heat flow and emissivity problems. The second goal is the development of a sufficiently robust probe for industrial use having a mechanism for applying heat to the thermometer stem in such a way as to exactly cancel existing heat flows. This 'dynamically compensated' probe will then be immune to errors caused by heat flows along the probe.

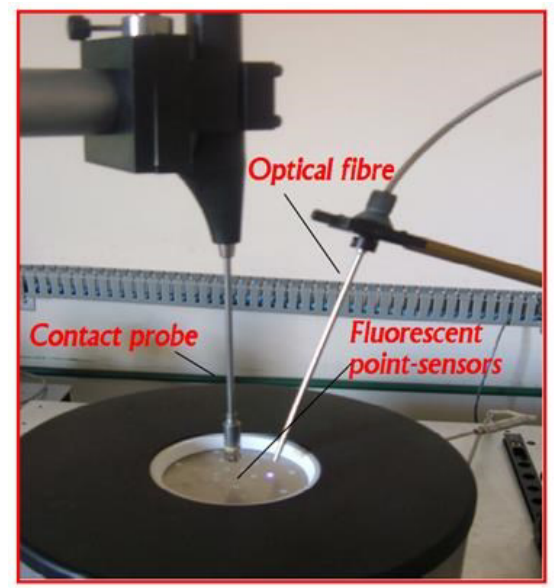

Figure 3. Prototype phosphor thermometer applied to surface temperature measurement.

\subsection{WP4: Traceable combustion temperature measurement}

Combustion is the only means of propulsion in the aerospace industry. Currently, the most accurate means of measuring temperatures of combustion processes are optical methods such as Coherent Anti-Stokes Raman Spectroscopy (CARS), Degenerate Four Wave Mixing
(DFWM) or more recently Laser Induced Grating Spectroscopy (LIGS) Thermographic phosphors are also sometimes deployed to measure temperature through direct introduction into the flame. However, despite the sophistication of these optical methods the absolute temperatures have uncertainties of typically between $5 \%$ and $10 \%$ of temperature. This situation limits the efficiency of combustion processes, makes efforts to improve efficiency extremely difficult [19], and hinders the improvement of heat engines and other combustion processes. The high temperatures generated by combustion processes have a direct influence on a variety of factors including chemical reaction rates, process efficiency, pollutant levels, product quality, and rate of failure mechanisms [20]. It is therefore of great importance to determine the temperature with the best possible accuracy. Thermocouples are still widely used in this context due to their simplicity and low cost, and a large proportion of traceability in the combustion industry is via corrected thermocouples. However, thermocouple gas thermometry is subject to numerous errors resulting from the complex interaction between the thermocouple and its environment [21]. Non-contact laser diagnostic techniques avoid these problems but are generally technically complex, and none have traceability to temperature standards. To advance the state of the art, a standard flame (Figure 4) will be commissioned, that has a known temperature traceable to ITS-90, and that can be transported to an end-user's site and used to validate the optical temperature measuring methods. The objective of the WP is to improve the uncertainty in flame and combustion temperature measurement by a factor of 10 when compared to current methods.

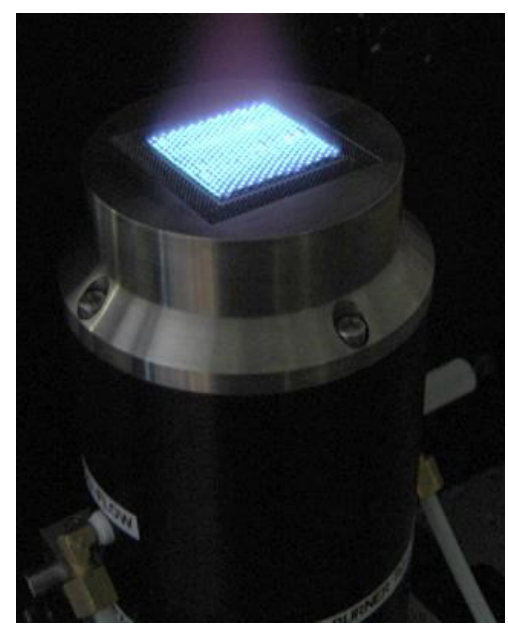

Figure 4. Portable standard flame provided by burning a well characterised fuel/air mixture with a highly uniform post flame composition.

\section{The consortium}

The project Consortium brings together the leading European NMIs and DIs in high accuracy temperature measurement: they are complemented by a number of research institutes and companies that bring their specific knowledge and experience. Overall, the consortium brings 
together complementary world leading skills of experts within the project partner organisations to address a broad range of industrial temperature measurement challenges. In total, 9 NMIs/DIs, 4 research institutes, and 5 enterprises are included.

In all WPs, the integrated involvement of NMIs will ensure traceability to the ITS-90. For the improved temperature sensor developments in WP1 and WP2, the complementary expertise of JV (Norway, radiation thermometry), NPL (UK, thermocouples), PTB (Germany, thermocouples), and UCAM (UK, industrial thermocouples) will be augmented by the industrial experience of CCPI (UK, thermocouple manufacturer). BRML (Romania, NMI), MUT (Germany, industrial furnace manufacturer), AFRC (UK, Advanced Manufacturing Research Centre), and Elkem (Norway, silicon and carbon processing) will facilitate access to EU industry for sensor trials. In WP3 for improved surface contact temperature measurement, the complementary capabilities of INRIM (Italy, fluorescence thermometry), CMI (Czech Republic, dynamically compensated temperature probes), DTI (Denmark, surface temperature measurement), and NPL (fluorescence thermometry, laser diagnostics) will be brought to bear on new surface temperature measurement techniques, which will be directly demonstrated in high value manufacturing processes at Gamma Forgiati (Italy, forging) and BAE

Systems (UK, marine and aerospace manufacturing). In WP4, combustion thermometry will be, for the first time, put on a traceable footing and made available to EU industry. NPL (with expertise in combustion thermometry and laser diagnostics) will develop a portable standard flame, and the complementary combustion temperature measurement expertise of CEM (Spain, radiation thermometry), DTU (Denmark, UV flame thermometry), Universidad Carlos III (Spain,

Fourier transform Infra-red spectroscopy), and Oxford University (UK, DFWM and LIGS laser based thermometry) will enable a thorough metrological characterization to provide a robust, traceable flame standard. In terms of immediate impact, the universities are the principal linkage with industry in WP4. WP5, concerned with impact and dissemination, will be led by AFRC who are ideally placed for such an activity: as part of the UK's High Value Manufacturing Catapult (a centre of excellence for stimulating innovation) they are supported by a number of high profile aerospace manufacturing companies. AFRC will also provide access to a number of full-scale manufacturing and heat treatment facilities to consortium members.

\section{Summary}

In summary, this project will:

- Develop novel low drift temperature sensors for enhanced production and temperature control with a target of in-process traceable uncertainty better than $3{ }^{\circ} \mathrm{C}$ at temperatures around $1450{ }^{\circ} \mathrm{C}$, and better than $5{ }^{\circ} \mathrm{C}$ at temperatures $>2000{ }^{\circ} \mathrm{C}$ over about 3 months continuous use.
- Develop non-drift contact sensors optimised for heat treatment applications to temperatures around $1350{ }^{\circ} \mathrm{C}$, having the ability to remain in service with a stability of better than $1{ }^{\circ} \mathrm{C}$ for at least 6 months.

- Develop traceable surface temperature measurement methods to enhance materials/chemical processing to around $500{ }^{\circ} \mathrm{C}$. The methods should allow the calibration of surface temperature sensors, using at least one novel surface temperature approach.

- Develop an in-situ combustion standard of known temperature for the validation of flame temperatures with an uncertainty a factor of 10 lower than current methods and be tested in at least two industrial settings.

\section{Acknowledgments}

This article describes the EMPIR project 14IND04 'EMPRESS'. EMPIR is jointly funded by the participating countries within EURAMET and the European Union. C Crown Copyright 2015. Reproduced by permission of the Queen's Controller of HMSO and the Queen's Printer for Scotland.

\section{References}

[1] G. Machin, K. Anhalt, M. Battuello, F. Bourson, P. Dekker, A. Diril, F. Edler, C.J. Elliott, F. Girard, A. Greenen, L. Kňazovická, D. Lowe, P. Pavlásek, J. V.

Pearce, M. Sadli, R. Strnad, M. Seifert, E.M. Vuelban, The European project on high temperature measurement solutions in industry (HiTeMS) - a summary of achievements, Measurement 2015 (in press) [2] $\mathrm{H}$. Preston-Thomas, The International Temperature Scale of 1990 (ITS-90), Metrologia 27 (1990) 3-10; erratum: Metrologia 27 (1990) 107

[3] FWC Sector Competitiveness Studies Competitiveness of the EU Aerospace Industry with focus on Aeronautics Industry, ENTR/06/054 (ECORYS study for European Commission)

[4] Strategic Research Agenda, Volume 1, Advisory Council for Aeronautics in Europe, October 2004

[5] Aerospace Materials, Edited by B. Cantor, P. Grant, H. Assender, Taylor \& Francis 2001. ISBN 9780750307420

[6] 2008 Addendum to the Strategic Research Agenda, Advisory Council for Aeronautics in Europe [7] Factories of the future: European Commission multiannual roadmap for the contractual PPP under Horizon 2020, Policy Research document prepared by EFFRA; ISBN 978-9279-31238-0

[8] Aerospace Material Specification (AMS) 2750 REV. E - Pyrometry

[9] Thermocouple Temperature Measurement, P.A. Kinzie, John Wiley \& Sons, 1973. ISBN 0-47148080-0

[10] ASTM E1751/E1751M - 09 Standard Guide for Temperature Electromotive Force (emf) Tables for Non- 
Letter Designated Thermocouple Combinations

[11] G. Machin, Twelve years of high temperature fixed point research: a review, AIP Conf. Proc. 1552, 305 (2013); DOI 10.1063/1.4821383

[12] O. Ongrai, J.V. Pearce, G. Machin, S.J. Sweeney, Self-calibration of a W/Re thermocouple using a miniature $\mathrm{Ru}-\mathrm{C} \quad\left(1954{ }^{\circ} \mathrm{C}\right)$ eutectic cell, 9th International Temperature Symposium, AIP Conf. Proc. 1552, 504

(2013)

[13] J.V. Pearce, C.J. Elliott, G. Machin, O. Ongrai, Selfvalidating Type $\mathrm{C}$ thermocouples to $2300{ }^{\circ} \mathrm{C}$ using high temperature fixed points, 9th International Temperature Symposium, AIP Conf. Proc. 1552, 595 (2013) [14] C. Elliott, J. Pearce, G. Machin, C. Schwarz, R. Lindner, Self-validating thermocouples for assured temperature measurement confidence and extended useful life, Proc. 12th European Conference on Spacecraft structures, materials and environmental testing, ESA Communications med. I Ouwehand, 2012 ESA, ISBN 978-92-9092-255-1 (2012)

[15] EUROMET Project No. 635 Final Report: Comparison of the reference surface temperature apparatus at NMIs by comparison of transfer surface temperature standards, E. András, November 2003 [16] R. Morice, E. András, E. Devin, T. Kovacs, Contribution for the calibration and the use of surface temperature sensors, in Proceedings of TEMPMEKO 2001, 8th International Symposium on Temperature and Thermal Measurements in Industry and Science, ed. By B. Fellmuth, J. Seidel, G. Scholz (VDE Verlag, Berlin, 2002), pp. 1111-1116

[17] BS EN ISO 8502-4:2000 Preparation of steel substrates before application of paints and related products - Tests for the assessment of surface cleanliness - Part 4: Guidance on the estimation of the probability of condensation prior to paint application.

[18] S.W. Allison and G.T. Gillies, Remote thermometry with thermographic phosphors: Instrumentation and applications, Rev. Sci. Instrum. 68(7) (1997) 2615-2650 [19] Reduction of emissions and energy utilisation of coke oven underfiring heating systems through advanced diagnostics and control (Ecocarb), European Commission Research Fund for Coal and Steel, M. Saiepour, J. Delinchant, J. Soons, F. Huhn, J. Morris, Final Report. ISBN 978-92-79-29187-6

[20] G. Sutton, A. Levick, G. Edwards, and D. Greenhalgh, A combustion temperature and species standard for the calibration of laser diagnostic techniques, Combustion and Flame 147 (2006) 39-48

[21] J.C. Jones, Suggestions Towards Improved Reliability of Thermocouple Temperature Measurement in Combustion Tests, in Thermal Measurements: The Foundation of Fire Standards, Gritzo LA, Alvares N, ASTM STP1427 (2003) 